08

\title{
Ферромагнитных резонанс в прохождении электромагнитных волн через металлические сверхрешетки
}

\author{
(C) А.Б. Ринкевич, Е.А. Кузнецов, Д.В. Перов, М.А. Миляев, Л.Н. Ромашев \\ Институт фризики металлов им. М.Н. Михеева УрО РАН, \\ 620108 Екатеринбург, Россия \\ e-mail: rin@imp.uran.ru
}

Поступило в Редакцию 21 июля 2020 г.

В окончательной редакции 17 декабря 2020 г.

Принято к публикации 17 декабря 2020 г.

Исследованы вызванные ферромагнитным резонансом изменения коэффициента прохождения микроволн с частотами от 26 до $38 \mathrm{GHz}$ через пленки $\mathrm{Fe}$ и сверхрешетки $\mathrm{Fe} / \mathrm{Cr}$. Форма резонансной линии описана в модели, в которой ее асимметрия получена добавлением лоренцевой кривой дисперсии к кривой поглощения. Показано, что форма линии для сверхрешеток со сплошными слоями $\mathrm{Fe}$ и $\mathrm{Cr}$, a также для пленок $\mathrm{Fe}$ хорошо описана в этой модели. Однако для сверхрешеток с тонкими слоями $\mathrm{Fe}$ или $\mathrm{Cr}$ наблюдается лишь качественное соответствие. В полях, меньших поля ферромагнитного резонанса, для сверхрешеток, обладающих гигантским магниторезистивным эффектом, наблюдается существенное отличие полевой зависимости экспериментально измеренного коэффициента прохождения от модели.

Ключевые слова: металлические сверхрешетки, ферромагнитный резонанс, микроволновой гигантский магниторезистивный эффект.

DOI: $10.21883 /$ JTF.2021.06.50871.230-20

\section{Введение}

Микроволновой гигантский магниторезистивный эффект ( $\mu \mathrm{GMR})$, и ферромагнитный резонанс (FMR) являются основными физическими причинами, влияющими на микроволновые свойства магнитных металлических пленок и наноструктур [1-4]. Изучение прохождения волн стало одним из эффективных методов исследования как $\mu \mathrm{GMR}$, так и (FMR). Этим методом исследованы сверхрешетки $\mathrm{Fe} / \mathrm{Cr}[3], \mathrm{Co} / \mathrm{Cu}[5,6]$, пленки из металлических нанокомпозитов[7]. Подобным методом на частотах 0.4-1 GHz была реализована геометрия эксперимента, в которой микроволновые токи протекают перпендикулярно плоскости слоев сверхрешетки [8]. Гигантский магниторезистивный эффект (GMR) наблюдался в инфракрасном диапазоне длин волн [9]. В микроволновом диапазоне была успешно применена методика исследования отраженных волн [10-12].

Метод прохождения микроволн хорошо разработан, и проведено сравнение результатов, полученных этим методом с другими, такими как исследование в обычном резонансном спектрометре, с методом магнитооптического эффекта Керра, в отношении поля резонанса и ширины линии $[13,14]$. Спектры FMR в металлических наноструктурах подробно исследованы как теоретически, так и экспериментально [15-18]. Было установлено, что межслоевое обменное взаимодействие оказывает очень значительное влияние на поле однородной моды резонанса и на существование неоднородных мод. Спектр FMR исследован экспериментально в сверхрешетках $\mathrm{Fe} / \mathrm{Cr}$ методом прохождения микроволн [19].
Совместное наблюдение особенностей прохождения микроволн при условиях как $\mu \mathrm{GMR}$, так и FMR осуществлено в работах [20,21] для нескольких типов сверхрешеток $\mathrm{Fe} / \mathrm{Cr}$ и пленок железа. Были построены частотные зависимости амплитуды и ширины линии FMR. Для сверхрешеток с тонкими слоями $\mathrm{Cr}$, когда сплошность слоя не гарантирована, FMR в прохождении волн наблюдался, но линия была меньшей амплитуды и большей ширины, чем для сверхрешеток со сплошными слоями.

Известно, что форма резонансной линии в проводящей среде асимметрична [22,23] из-за влияния вихревых токов. Асимметрия наблюдается не только для металлических пленок и наноструктур [21,24], но и для других проводящих объектов [25,26]. Исследование линии FMR при спиновой накачке позволило определить времена спиновой релаксации [27]. Согласно [23,28,29], степень асимметрии линии резонанса зависит от соотношения времени, которое требуется электрону для пересечения всего образца и времени, необходимого электрону для диффузии сквозь скин-слой. Форма линии FMR при прохождении волны через металлическую наноструктуру не исследована подробно. Эта задача ставится в настоящей работе. На частотах $26-38 \mathrm{GHz}$ будет исследовано прохождение микроволн через пленки железа и наноструктуры $\mathrm{Fe} / \mathrm{Cr}$ с различными толщинами слоев и разными типами магнитного упорядочения. Во всех образцах слои Fе упорядочены ферромагнитно. У сверхрешеток с непрерывными слоями Fе без внешнего магнитного поля реализуется антипараллельное, неколлинеарное или близкое к антипараллельному упорядочение магнитных моментов соседних слоев Fe. У наноструктур с тонкими 
Список образцов

\begin{tabular}{|c|c|c|c|c|}
\hline $\begin{array}{c}\text { № } \\
\text { образца }\end{array}$ & Композиция образца & $H_{s}, \mathrm{kOe}$ & $\begin{array}{c}\text { Тип межслоевого } \\
\text { магнитного упорядочения }\end{array}$ & $\begin{array}{c}\text { Характеристика } \\
\text { образца }\end{array}$ \\
\hline 1 & $\mathrm{Cr}(3) / \mathrm{Fe}(10) / \mathrm{Cr}(7) / \mathrm{Al}_{2} \mathrm{O}_{3}$ & & - & \multirow{3}{*}{ Пленки Fe } \\
\hline 2 & $\mathrm{Cr}(1.0) / \mathrm{Fe}(57.3) / \mathrm{Al}_{2} \mathrm{O}_{3}$ & 0.03 & - & \\
\hline 3 & $\mathrm{Cr}(2.0) / \mathrm{Fe}(82) / \mathrm{Al}_{2} \mathrm{O}_{3}$ & 0.08 & - & \\
\hline 4 & {$[\mathrm{Cr}(10.5) / \mathrm{Fe}(14.6) / \mathrm{Cr}(4.3) / \mathrm{Fe}(14.4) / \mathrm{Cr}(9.8)] / \mathrm{Al}_{2} \mathrm{O}_{3}$} & & - & $\begin{array}{l}\text { Две слабо связанные } \\
\text { пленки } \mathrm{Fe}\end{array}$ \\
\hline 5 & {$[\mathrm{Cr}(1.9) / \mathrm{Fe}(2.3)]_{12} / \mathrm{Cr}(8) / \mathrm{MgO}$} & 6.8 & неколлинеарное & \multirow{4}{*}{$\begin{array}{l}\text { Сверхрешетки } \\
\text { со сплошными } \\
\text { слоями }\end{array}$} \\
\hline 6 & {$[\mathrm{Cr}(1.3) / \mathrm{Fe}(2.4)]_{8} / \mathrm{Cr}(8.2) / \mathrm{MgO}$} & 12.0 & антипараллелльное & \\
\hline 7 & {$[\mathrm{Cr}(1.2) / \mathrm{Fe}(2.3)]_{16} / \mathrm{Cr}(7.7) / \mathrm{MgO}$} & 12.6 & антипараллельное & \\
\hline 8 & {$[\mathrm{Cr}(1.8) / \mathrm{Fe}(2.8)]_{12} / \mathrm{Cr}(7.7) / \mathrm{MgO}$} & 4.9 & $\begin{array}{c}\text { неколлинеарное, } \\
\text { близкое к параллельному }\end{array}$ & \\
\hline 9 & {$[\mathrm{Cr}(0.71) / \mathrm{Fe}(2.6)]_{12} / \mathrm{Cr}(6.5) / \mathrm{Al}_{2} \mathrm{O}_{3}$} & 7.6 & неоднородное & $\begin{array}{l}\text { Сверхрешетка } \\
\text { с тонкими слоями } \mathrm{Cr}\end{array}$ \\
\hline 10 & $\mathrm{Cr}(0.6) /[\mathrm{Cr}(2) / \mathrm{Fe}(0.55)]_{30} / \mathrm{Cr}(8) / \mathrm{MgO}$ & 2.3 & неоднородное & $\begin{array}{l}\text { Сверхрешетка } \\
\text { с тонкими слоями Fe }\end{array}$ \\
\hline
\end{tabular}

Примечани е. Толщины слоев в нанометрах указаны в круглых скобках

несплошными слоями реализуется более сложное неколлинеарное упорядочение слоев и кластеров Fе. Будет выполнен анализ формы линии резонансов, определена ширина линии и получены значения константы затухания Гильберта в магнитной системе.

\section{1. Образцы и методика микроволновых измерений}

Образцы пленок и наноструктур выращены на установке „Катунь-С“ методом молекулярно-лучевой эпитаксии. Образцы выращены в вакууме $\sim 10^{-6} \mathrm{~Pa}$ со скоростью $0.1-0.2 \mathrm{~nm} / \mathrm{min}$ на монокристаллических подложках из сапфира $\mathrm{Al}_{2} \mathrm{O}_{3}$ и оксида магния $\mathrm{MgO}$. В настоящей работе исследовано большое количество образцов разных толщин, с различной магнитной структурой и различными типами межслоевых взаимодействий. Среди них пленки железа с толщиной от 10 до $82 \mathrm{~nm}$, выращенные с буферным слоем хрома (толщиной от 1 до $10 \mathrm{~nm}$ ) и покрытые слоем хрома толщиной 4-7 nm. Были выращены и исследованы наноструктуры и сверхрешетки системы $\mathrm{Fe} / \mathrm{Cr}$ с различной номинальной толщиной слоев, выбранной так, чтобы реализовались либо гарантированно сплошные слои $\mathrm{Fe}$, либо слои с минимальной толщиной в 1-2 монослоя, при которой слой Fe еще сплошной, но со значительной неоднородностью. Толщина слоев $\mathrm{Cr}$ сверхрешеток выбиралась таким образом, чтобы реализовались различные типы межслоевого магнитного упорядочения, например, с параллельным направлением магнитных моментов соседних слоев Fe и с антипараллельным. Такие сверхрешетки обладают константой межслоевого обменного взаимодействия с разными знаками. Наибольшую величину GMR имеют сверхрешетки с антипараллельным упорядочением слоев. Кроме этого, один из образцов имеет скошенную структуру, в которой реализуется неколлинеарное упорядочение магнитных моментов соседних слоев [30]. Образцы с очень тонкими слоями менее 05-0.7 nm имеют сложное магнитное упорядочение даже в пределах одного несплошного слоя. Список образцов, использованных в работе, приведен в таблице. В таблице приведены значения поля насыщения $H_{s}$.

Приготовленные образцы были исследованы методом малоугловой рентгеновской дифракции с тем, чтобы выяснить состояние интерфейсов, а для сверхрешеток еще и определить период повторения слоев. Структура образцов исследована методом просвечивающей электронной микроскопии на микроскопе JEM-200CX при увеличении до 50000 . В результате исследования было установлено, что образцы сверхрешеток со сплошными слоями имеют толщину слоев, близкую к номинальной, однородную структуру и четкие границы между слоями. Для большинства образцов на сквид-магнитометре MPMS-5XL выполнены измерения кривых намагничивания при комнатной температуре. Результаты этих измерений, в частности, величина намагниченности насыщения, будут использованы при анализе результатов микроволновых измерений. Для сверхрешеток, обладающих GMR, выполнены магниторезистивные измерения.

Микроволновые исследования выполнены методом прохождения микроволн через пленки и наноструктуры. Схема расположения образца при микроволновых измерениях показана на рис. 1. Образец полностью пе- 


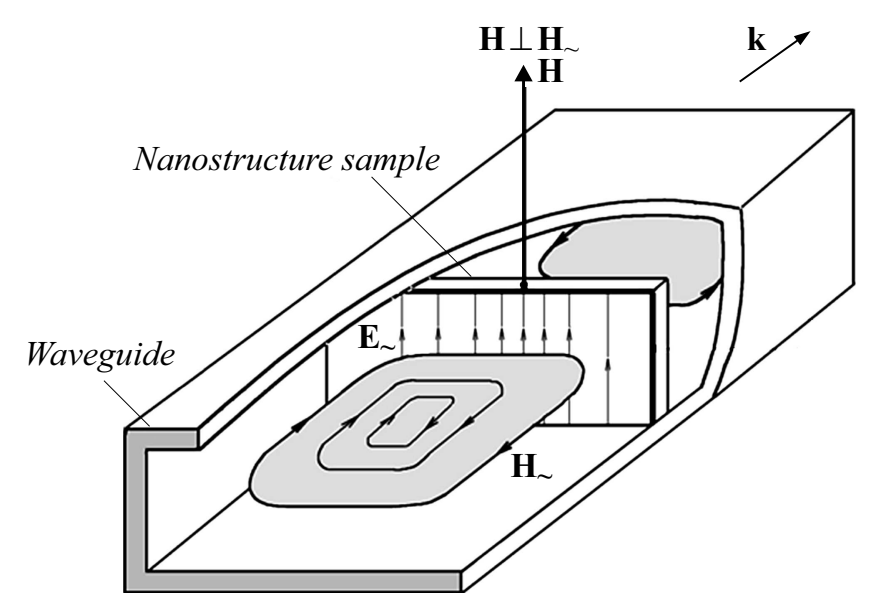

Рис. 1. Схема расположения образца при микроволновых измерениях.

регораживает поперечное сечение прямоугольного волновода с размерами $7.2 \times 3.6 \mathrm{~mm}$. Края образца смазаны токопроводящим клеем, чтобы предотвратить просачивание волны мимо образца. В данной методике очень важно, чтобы образец был единственной существенной неоднородностью в микроволновом тракте. При измерениях реализовались следующие направления векторов полей. Направление волнового вектора q перпендикулярно плоскости образца. Вектор микроволнового электрического поля $\mathbf{E}_{\sim}$ волны $\mathrm{TE}_{10}$ лежит в плоскости образца; его направление параллельно меньшей стенке волновода. Вектор микроволнового магнитного поля $\mathbf{H}_{\sim}$ лежит в плоскости, перпендикулярной образцу. Постоянное магнитное поле Н ориентировано перпендикулярно микроволновому, $H \perp H_{\sim}$. При $H \perp H_{\sim}$ реализуются условия существования FMR [31]. Измерялись следующие величины: модуль коэффициента прохождения $|D(H)|$ и его изменение в постоянном магнитном поле $d_{m}=(|D(H)|-|D(0)|) /|D(0)|$. Важно заметить, что в отличие от стандартной методики наблюдения FMR в спектрометрах, здесь не используется модуляционная методика и поэтому регистрируются изменения самого коэффициента прохождения, а не его производная. Микроволновые измерения выполнены в интервале частот от 26 до $38 \mathrm{GHz}$ с помощью измерителя амплитудночастотных характеристик Р2-65.

\section{2. Результаты микроволновых измерений}

Рассмотрим сначала результаты исследований тонкой пленки $\mathrm{Fe}$. Измерения прохождения микроволн выполнены для образца следующего состава $\mathrm{Cr}(3) / \mathrm{Fe}(10) / \mathrm{Cr}(7) / \mathrm{Al}_{2} \mathrm{O}_{3}$ (образец 1). Эта пленка $\mathrm{Fe}$ толщиной $10 \mathrm{~nm}$ выращена на подложке из сапфира с буферным слоем $\mathrm{Cr}$ толщиной $7 \mathrm{~nm}$ и покрыта сверху защитным слоем $\mathrm{Cr}$ толщиной $3 \mathrm{~nm}$. Здесь и далее толщины слоев в нанометрах указаны в круглых скобках. Результаты измерений зависимостей модуля коэффициента прохождения от магнитного поля, выполненных на нескольких частотах, показаны на рис. 2, a. Разумеется, в этом образце $\mu \mathrm{GMR}$ отсутствует и видны резонансные минимумы, вызванные FMR. Линия резонанса смещается в более сильные поля при увеличении частоты. С увеличением частоты амплитуда резонанса увеличивается. Если FMR наблюдается в состоянии магнитного насыщения, то при нашем расположении полей поле резонанса находится по формуле Киттеля:

$$
\omega=\gamma\left[H\left(H+4 \pi M_{s}\right)\right]^{1 / 2}, \quad H>H_{s},
$$

где $\omega=2 \pi f-$ круговая частота волны, $\gamma-$ магнитомеханическое отношение, $M_{s}$ - намагниченность насыщения, $H_{s}$ - поле насыщения. Хорошо известно, что для ферромагнитных металлических пленок эта формула точно выполняется. Отметим, что резонансная линия резко асимметрична. После резонансного минимума, вызванного поглощением электромагнитных волн в условиях FMR, наблюдается максимум. В разд. 4 настоящей работы будет выполнен анализ формы линии на основе модели, в которой асимметрия возникает из-за суперпозиции лоренцевых линий поглощения и дисперсии.

Теперь рассмотрим сверхрешетки с непрерывными слоями. Межслоевое обменное взаимодействие и магнитная структура оказывают на спектр самое существенное влияние. В работах $[15,16]$ на основании решения уравнения движения магнитного момента был рассчитан спектр FMR. В сверхрешетках реализуется сложный спектр магнитных колебаний, состоящий из нескольких ветвей. Колебания, происходящие с одинаковой фазой для всех магнитных моментов, называют однородной, или акустической модой. Кроме акустической, есть еще оптическая мода, при которой магнитные моменты соседних слоев колеблются в противофазе, а также неоднородные моды колебаний, в которых осуществляется другой фазовый сдвиг между колебаниями слоев. В экспериментах, описанных выше, проявляется только акустическая мода колебаний. Уравнения спектра частот акустической моды записываются различным образом для насыщенного и ненасыщенного состояний:

$$
\begin{array}{ll}
\omega=\gamma M\left[2 C\left(2 C+K_{\text {eff }}\right)\right]^{1 / 2}, & H \leq H_{s}, \\
\omega=\gamma\left[H\left(H+K_{\text {eff }} M_{s}\right)\right]^{1 / 2}, & H>H_{s} .
\end{array}
$$

Величина $C$ выражается через обменные константы билинейного $J_{1}$ и биквадратичного $J_{2}$ обмена

$$
C=\frac{2}{d M_{s}^{2}}\left[J_{1}-2 J_{2}\left(1-2 \frac{M^{2}}{M_{s}^{2}}\right)\right]
$$

В выражении (3) $d$ - это толщина ферромагнитного слоя наноструктуры. Константа $K_{\text {eff }}$ учитывает влияние 

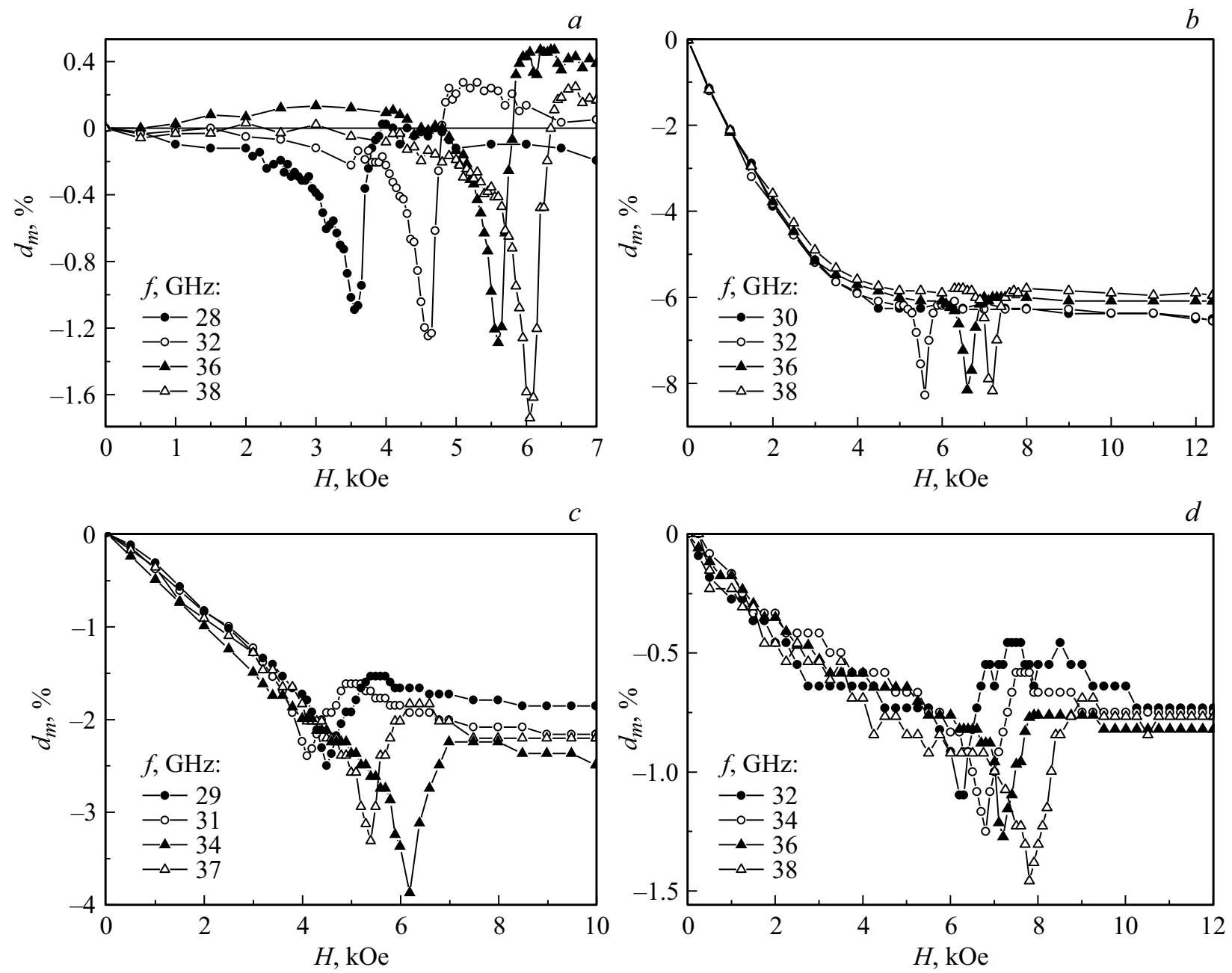

Рис. 2. Зависимости коэффициента прохождения через наноструктуру от магнитного поля, измеренные на нескольких частотах миллиметрового диапазона: $a$ - пленка $\mathrm{Fe}$, образец 1 состава $\mathrm{Cr}(3) / \mathrm{Fe}(10) / \mathrm{Cr}(7) / \mathrm{Al}_{2} \mathrm{O}_{3} ; b-$ сверхрешетка со сплошными слоями $\mathrm{Fe}$ и $\mathrm{Cr}$ образец 5 состава $[\mathrm{Cr}(1.9) / \mathrm{Fe}(2.3)]_{12} / \mathrm{Cr}(8) / \mathrm{MgO} ; c$ - сверхрешетка с тонкими слоями $\mathrm{Cr}$ образец 9 $[\mathrm{Cr}(0.71) / \mathrm{Fe}(2.6)]_{12} / \mathrm{Cr}(6.5) / \mathrm{Al}_{2} \mathrm{O}_{3} ; d$ - сверхрешетка с тонкими слоями $\mathrm{Fe}$ образец $10 \mathrm{Cr}(0.6) /[\mathrm{Cr}(2) / \mathrm{Fe}(0.55)]_{30} / \mathrm{Cr}(8) / \mathrm{MgO}$.

одноосной анизотропии. Согласно [15], для сверхрешеток $\mathrm{Fe} / \mathrm{Cr} K_{\mathrm{eff}} \approx 4 \pi$. Выражение (3) для спектра акустической моды FMR можно переписать в виде

$$
\begin{gathered}
\omega=2 \gamma m\left[\frac{J_{1}-2 J_{2}\left(1-2 m^{2}\right)}{d}\right. \\
\left.\times\left(\frac{J_{1}-2 J_{2}\left(1-2 m^{2}\right)}{d}+\pi M_{s}^{2}\right)\right]^{1 / 2}, \\
H \leq H_{s},
\end{gathered}
$$

где $m=M / M_{s}$,

$$
\omega=\mathcal{\gamma}\left[H\left(H+4 \pi M_{s}\right)\right]^{1 / 2}, \quad H>H_{s} .
$$

Выражение (5) эквивалентно формуле (1) для пленок. Спектр FMR сверхрешеток зависит от констант межслоевого обмена только в том случае, если резонанс приходится на ненасыщенное состояние сверхрешетки. Соответствие поля резонанса формулам (4) и (5) для различных сверхрешеток $\mathrm{Fe} / \mathrm{Cr}$ было проверено в $[19,21]$ и было установлено, что для пленок Fе и сверхрешеток со сплошными слоями формулы (4), (5) выполняются с точностью не хуже $1-2 \%$. Для сверхрешеток с тонкими и, возможно, не сплошными слоями Сr, отклонение от формулы (4) достигает 4\%. Далее мы рассмотрим форму линии FMR в прохождении микроволн. На рис. 2, $b$ показаны зависимости модуля коэффициента прохождения через сверхрешетку со сплошными слоями $\mathrm{Fe}$ и $\mathrm{Cr}$ (образец 5) состава $[\mathrm{Cr}(1.9) / \mathrm{Fe}(2.3)]_{12} / \mathrm{Cr}(8) / \mathrm{MgO}$. Для этой сверхрешетки поле насышения $H_{s}$ составляет $\sim 4.5 \mathrm{kOe}$, а поле FMR для рассматриваемых частот оказалось больше. Так что FMR в этом образце осуществляется в магнитном насыщении и применима формула (5), которая хорошо описывает спектр этого образца. Анализ формы линии для этого образца выполнен в разд. 3. Здесь отметим, что в этом случае, как и для пленки $\mathrm{Fe}$, в полях больше поля FMR $\mathrm{Hr}$ наблюдается максимум коэффициента прохождения. В несколь- 
ких образцах сверхрешеток поле FMR приходится на ненасыщенное состояние сверхрешетки. В этом случае амплитуда резонансной особенности мала, и велика ширина линии FMR $[19,21]$. В этом случае FMR реализуется на фоне изменений коэффициента прохождения, вызванных $\mu \mathrm{GMR}$. Такое осуществляется, например, в сверхрешетках состава $[\mathrm{Cr}(1.3) / \mathrm{Fe}(2.4)]_{8} / \mathrm{Cr}(8.2) / \mathrm{MgO}$ (образец 6), $[\mathrm{Cr}(1.2) / \mathrm{Fe}(2.3)]_{16} / \mathrm{Cr}(7.7) / \mathrm{MgO}$ (образец 7). Точность определения изменений $D$, вызванных FMR, невелика и в этом случае форма резонансной линии в настоящей работе не будет анализироваться.

Далее мы рассмотрим сверхрешетки с тонкими, возможно не сплошными слоями $\mathrm{Fe}$ и $\mathrm{Cr}$. Зависимости коэффициента прохождения через наноструктуру $[\mathrm{Cr}(0.71) / \mathrm{Fe}(2.6)]_{12} / \mathrm{Cr}(6.5) / \mathrm{Al} 2 \mathrm{O} 3$ от магнитного поля, измеренные на нескольких частотах миллиметрового диапазона, показаны на рис. 2,c. В этом образце с тонкими слоями хрома резонанс приходится на поля, близкие к полю насыщения магниторезистивного эффекта. Номинальная толщина слоев хрома $0.71 \mathrm{~nm}$ меньше толщины $0.9-1.0 \mathrm{~nm}$, соответствующей первому максимуму магниторезистивного эффекта. Поэтому величина $\mu \mathrm{GMR}$ в этом образце невелика, в насыщении она составляет, как видно из рис. $2, c$, около $2.5 \%$. После поля минимума в области резонанса на зависимостях присутствуют локальные максимумы, подобно тому, что наблюдалось для пленок $\mathrm{Fe}$ и сверхрешеток со сплошными слоями. Следует отметить, что ширина линии резонанса для этого образца намного больше, чем для ранее рассмотренных образцов. Вероятно, это связано с нарушениями слошности слоев хрома и возникающей из-за этого локальной магнитной неоднородностью. На рис. $2, d$ показаны зависимости коэффициента прохождения через сверхрешетку с тонкими слоями $\mathrm{Fe}$ образец $10 \mathrm{Cr}(0.6) /[\mathrm{Cr}(2) / \mathrm{Fe}(0.55)]_{30} / \mathrm{Cr}(8) / \mathrm{MgO}$. Эти зависимости похожи на предыдущий случай, что неудивительно, так как и в этом образце присутствует локальная магнитная неоднородность из-за малой толщины слоя $\mathrm{Fe}$. В обоих последних образцах велика ширина резонансной линии и мала ее амплитуда, в сравнении со сверхрешеткой со сплошными слоями.

\section{3. Влияние гигантского магниторезистивного эффекта}

В разд. 3 выполним расчет коэффициента прохождения микроволн через металлическую сверхрешетку, обладающую эффектом GMR. Расчет выполним в приближении эффективных параметров, в котором сверхрешетка заменяется однородной ферромагнитной металлической пластиной. Пластина имеет толщину, равную суммарной толщине слоев сверхрешетки, и эффективные динамические магнитную и диэлектрическую проницаемости. Эффект GMR изменяет проводимость и, следовательно, эффективную диэлектрическую проницаемость. Комплексный коэффициент прохождения D при нормальном падении плоской волны на слой [32]:

$$
D=\frac{2 Z_{1} \dot{Z}_{2}}{2 Z_{1} \dot{Z}_{2} \cos \left(\dot{k}_{2} d_{2}\right)+i\left[Z_{1}^{2}+\dot{Z}_{2}^{2}\right] \sin \left(\dot{k}_{2} d_{2}\right)} .
$$

В формуле (6) использованы следующие обозначения: $Z_{1}$ - импеданс среды, окружающей с обеих сторон ферромагнитную пластину толщиной $d_{2}$, которая имеет комплексный импеданс

$$
\dot{Z}_{2}=\operatorname{Re} \dot{Z}_{2}+i \operatorname{Im} \dot{Z}_{2}=\sqrt{\frac{\mu_{0} \dot{\mu}_{\mathrm{eff}}}{\varepsilon_{0} \dot{\varepsilon}}}
$$

где $\varepsilon_{0}-$ диэлектрическая постоянная, $\mu_{0}-$ магнитная постоянная, $\dot{\varepsilon}-$ комплексная диэлектрическая проницаемость, $\mu_{\mathrm{eff}}-$ комплексная эффективная магнитная проницаемость.

Комплексное волновое число для ферромагнитного диэлектрика с учетом потерь [31]:

$$
\begin{gathered}
\dot{k}_{2}=\operatorname{Re} \dot{k}_{2}-i \operatorname{Im} \dot{k}_{2}=k_{2}^{\prime}-i k_{2}^{\prime \prime}, \\
k_{2}^{\prime}=\frac{\omega}{c_{0}} \sqrt{\frac{|\dot{\varepsilon}|\left|\dot{\mu}_{\mathrm{eff}}\right|+\varepsilon^{\prime} \mu_{\mathrm{eff}}^{\prime}-\varepsilon^{\prime \prime} \mu_{\mathrm{eff}}^{\prime \prime}}{2}}, \\
k_{2}^{\prime \prime}=\frac{\omega}{c_{0}} \sqrt{\frac{|\dot{\varepsilon}|\left|\dot{\mu}_{\mathrm{eff}}\right|-\varepsilon^{\prime} \mu_{\mathrm{eff}}^{\prime}+\varepsilon^{\prime \prime} \mu_{\mathrm{eff}}^{\prime \prime}}{2}}, \\
c_{0}=\frac{1}{\sqrt{\varepsilon_{0} \mu_{0}}},
\end{gathered}
$$

где $c_{0}-$ скорость распространения электромагнитных волн в вакууме, $\omega-$ угловая частота.

Комплексные параметры среды:

$$
\begin{gathered}
\mu_{\mathrm{eff}}=\operatorname{Re} \mu_{\mathrm{eff}}-i \operatorname{Im} \dot{\mu}_{\mathrm{eff}}=\mu_{\mathrm{eff}}^{\prime}-i \mu_{\mathrm{eff}}^{\prime \prime}, \\
\dot{\varepsilon}=\operatorname{Re} \dot{\varepsilon}-i \operatorname{Im} \dot{\varepsilon}=\varepsilon^{\prime}-i \varepsilon^{\prime \prime},
\end{gathered}
$$

где

$$
\dot{\varepsilon}=\varepsilon^{\prime}-i \varepsilon^{\prime \prime}=\varepsilon^{\prime}-i \frac{\sigma}{\omega \varepsilon_{0}} .
$$

Эффективная магнитная проницаемость для случая $H \perp H_{\sim}$ выражается формулой [31]

$$
\mu_{\mathrm{eff}}=\mu_{\mathrm{eff}}^{\prime}-i \mu_{\mathrm{eff}}^{\prime \prime}=\mu-\frac{\dot{\mu}_{a}^{2}}{\dot{\mu}} .
$$

Тензор динамической магнитной проницаемости записывается следующим образом:

$$
\begin{aligned}
\overleftrightarrow{\boldsymbol{\mu}} & =\overleftrightarrow{\mathbf{I}}+4 \pi \overleftrightarrow{\chi}=\left(\begin{array}{ccc}
\dot{\mu} & i \dot{\mu}_{a} & 0 \\
-i \dot{\mu}_{a} & \dot{\mu} & 0 \\
0 & 0 & \dot{\mu}_{\|}
\end{array}\right) \\
& =\left(\begin{array}{ccc}
1 & 0 & 0 \\
0 & 1 & 0 \\
0 & 0 & 1
\end{array}\right)+4 \pi\left(\begin{array}{ccc}
\dot{\chi} & i \dot{\chi}_{a} & 0 \\
-i \dot{\chi}_{a} & \dot{\chi} & 0 \\
0 & 0 & \dot{\chi}_{\|}
\end{array}\right),
\end{aligned}
$$



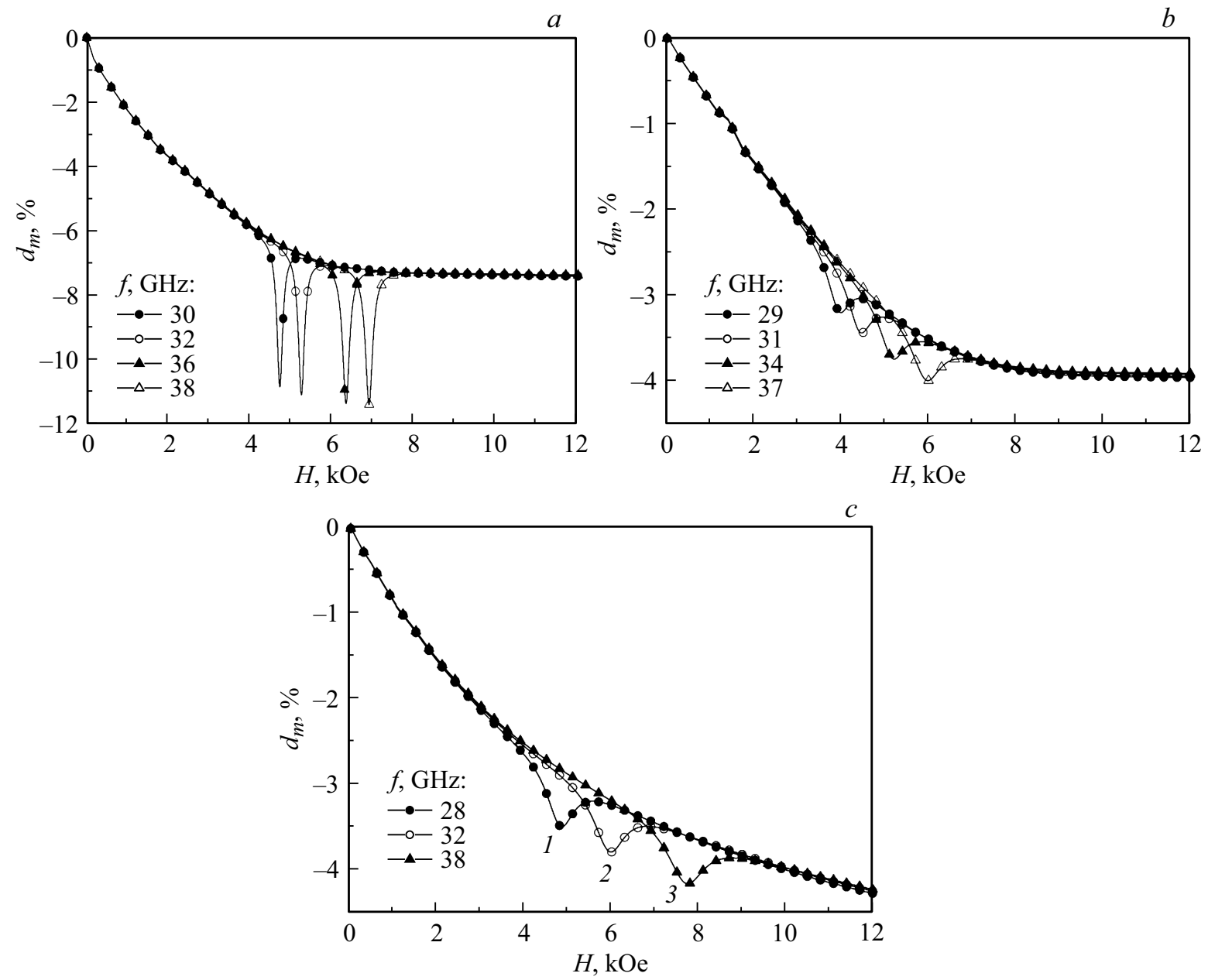

Рис. 3. Рассчитанная зависимость коэффициента прохождения от магнитного поля для трех сверхрешеток: $a-$ сверхрешетка со сплошными слоями $\mathrm{Fe}$ и $\mathrm{Cr}$ образец 5 состава $[\mathrm{Cr}(1.9) / \mathrm{Fe}(2.3)]_{12} / \mathrm{Cr}(8) / \mathrm{MgO} ; b-$ сверхрешетка с тонкими слоями Сr образец 9 $[\mathrm{Cr}(0.71) / \mathrm{Fe}(2.6)]_{12} / \mathrm{Cr}(6.5) / \mathrm{Al}_{2} \mathrm{O}_{3} ; c$ - сверхрешетка с тонкими слоями $\mathrm{Fe}$ образец $10 \mathrm{Cr}(0.6) /[\mathrm{Cr}(2) / \mathrm{Fe}(0.55)]_{30} / \mathrm{Cr}(8) / \mathrm{MgO}$.

где компоненты тензора динамической магнитной восприимчивости

$$
\begin{gathered}
\dot{\chi}=\chi^{\prime}-i \chi^{\prime \prime}, \quad \dot{\chi}_{a}=\chi_{a}^{\prime}, \\
\dot{\chi}_{\|}=\chi_{\|}^{\prime}-i \chi_{\|}^{\prime \prime}
\end{gathered}
$$

для линии лоренцевой формы можно рассчитать по формулам

$$
\begin{aligned}
& \chi^{\prime}=\frac{\gamma M_{s} \omega_{H}\left(\omega_{H}^{2}-\left(1-\alpha^{2}\right) \omega^{2}\right)}{\left(\omega_{H}^{2}-\left(1+\alpha^{2}\right) \omega^{2}\right)^{2}+4 \alpha^{2} \omega^{2} \omega_{H}^{2}}, \\
& \chi^{\prime \prime}=\frac{\alpha \gamma M_{s} \omega\left(\omega_{H}^{2}+\left(1+\alpha^{2}\right) \omega^{2}\right)}{\left(\omega_{H}^{2}-\left(1+\alpha^{2}\right) \omega^{2}\right)^{2}+4 \alpha^{2} \omega^{2} \omega_{H}^{2}}, \\
& \chi_{a}^{\prime}=\frac{\gamma M_{s} \omega\left(\omega_{H}^{2}-\left(1+\alpha^{2}\right) \omega^{2}\right)}{\left(\omega_{H}^{2}-\left(1+\alpha^{2}\right) \omega^{2}\right)^{2}+4 \alpha^{2} \omega^{2} \omega_{H}^{2}}, \\
& \chi_{a}^{\prime \prime}=\frac{2 \alpha \gamma M_{s} \omega^{2} \omega_{H}}{\left(\omega_{H}^{2}-\left(1+\alpha^{2}\right) \omega^{2}\right)^{2}+4 \alpha^{2} \omega^{2} \omega_{H}^{2}}, \\
& \chi_{\|}^{\prime}=\frac{\alpha^{2} \gamma M_{s} \omega_{H}}{\omega^{2}+\alpha^{2} \omega_{H}^{2}}, \quad \chi_{\|}^{\prime \prime}=\frac{\alpha \gamma M_{s} \omega}{\omega^{2}+\alpha^{2} \omega_{H}^{2}} .
\end{aligned}
$$

Здесь $\omega_{H}=\gamma H_{0}, \gamma-$ гиромагнитное отношение, $H_{-}$- постоянное магнитное поле, $\alpha$ - параметр диссипации, $M_{s}$ - намагниченность насыщения, $\sigma$ удельная электрическая проводимость. Детали расчета полевой зависимости коэффициента прохождения описаны в работе [33]. Здесь отметим, как были получены значения материальных параметров, входящих в приведенные выше формулы (7). Намагниченность насыщения $M_{s}$ определяется из магнитных измерений для каждого образца. Удельная электрическая проводимость находится из частотной зависимости коэффициента прохождения микроволн в нулевом магнитном поле по методике, описанной в [34]. В этой методике экспериментальная частотная зависимость коэффициента $D$ сопоставляется с зависимостью, рассчитанной по формуле (6) для случая нулевого внешнего поля. Выбирается значение проводимости $\sigma$, при котором различие между экспериментальной и рассчитанной зависимостями оказывается минимальным в смысле метода наименьших квадратов. Эффект GMR учитывается путем построения зависимости $\sigma=\sigma(H)$, исходя из результатов измерения магни- 


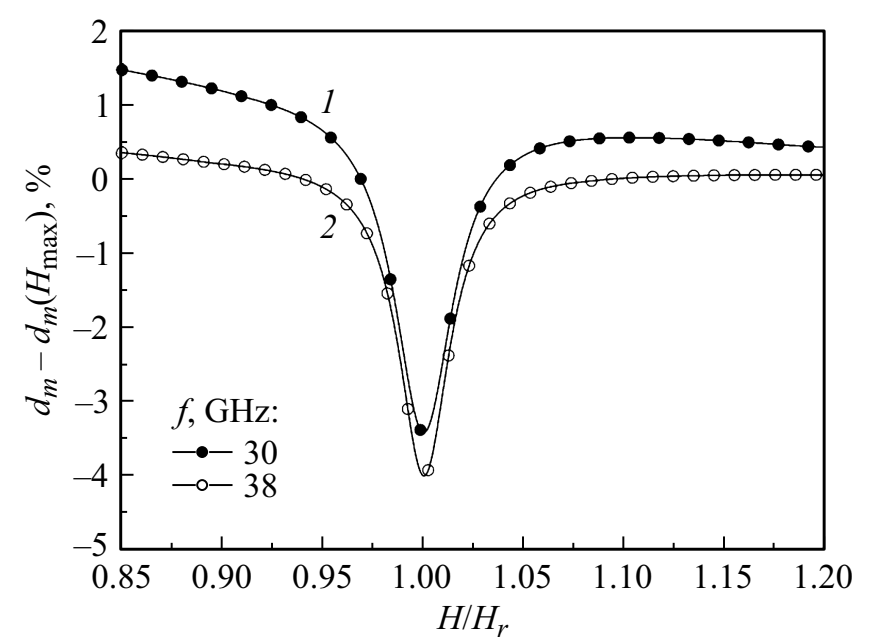

Рис. 4. Форма линии для сверхрешетки со сплошными слоями (образец 5), рассчитанная для двух частот.

тосопротивления. Эффективная постоянная затухания $\alpha$ определена из ширины линии FMR [31].

Результаты расчета полевой зависимости коэффициента прохождения показаны на рис. 3 для трех сверхрешеток: сверхрешетки со сплошными слоями $\mathrm{Fe}$ и $\mathrm{Cr}$ (образец 5 состава $\left.[\mathrm{Cr}(1.9) / \mathrm{Fe}(2.3)]_{12} / \mathrm{Cr}(8) / \mathrm{MgO}\right)$, сверхрешетки с тонкими слоями $\mathrm{Cr}$ (образец 9 состава $\left.[\mathrm{Cr}(0.71) / \mathrm{Fe}(2.6)]_{12} / \mathrm{Cr}(6.5) / \mathrm{Al}_{2} \mathrm{O}_{3}\right)$, сверхрешетки с тонкими слоями $\mathrm{Fe}$ (образец 10 состава $\mathrm{Cr}(0.6) /[\mathrm{Cr}(2) / \mathrm{Fe}(0.55)]_{30} / \mathrm{Cr}(8) / \mathrm{MgO}$. Символы на рис. 3 поставлены только для обозначения кривых. Расчеты выполнены с шагом 1-2Ое. Эти результаты сравним с данными эксперимента на рис. $2, b-d$ соответственно. Можно отметить некоторые черты, совпадающие в расчете и эксперименте. Поле резонанса в расчете для одинаковых частот близко к измеренному, так, что спектр резонанса воспроизводится корректно. Как в расчете, так и на эксперименте FMR проявляется как минимум на зависимости, происходящий из-за поглощения микроволновой мощности. Величина резонансных изменений лишь по порядку величины соответствует измеренным значениям. Разумеется, относительная ширина резонансной линии для образцов с тонкими слоями $\mathrm{Fe}$ и $\mathrm{Cr}$ из-за магнитной неоднородности больше, чем для образца 5 со сплошными слоями. Структура формулы (7), содержащая нелинейные зависимости, не дает возможности рассчитать отдельно вклады $\mu \mathrm{GMR}$ и FMR. Присутствие эффекта $\mu \mathrm{GMR}$ оказывает влияние на форму резонансной линии, особенно для образцов 9 и 10 с тонкими слоями, когда поле FMR приходится на область полей меньше магнитного насыщения. Можно заметить, что асимметрия у экспериментальных зависимостей выражена сильнее, чем у расчетных. Это проявляется, в частности, в наличие у экспериментальных зависимостей максимума коэффициента прохождения в полях, несколько больших поля минимума.
Влияние эффекта $\mu \mathrm{GMR}$ на форму резонансной линии иллюстрирует рис. 4, на котором представлен результат расчета коэффициента прохождения для образца 5. Этот образец выбран, исходя из того соображения, что на частоте $f=30 \mathrm{GHz}$ поле резонанса $H_{r}$ приходится на ненасыщенное состояние сверхрешетки $H_{r}<H_{s}$, а на частоте $38 \mathrm{GHz}$ - в состоянии, близком к магнитному насыщению $H_{r} \approx H_{s}$. Заметим, что поле насыщения $H_{s}$ не зависит от частоты микроволн, а поле резонанса смещается в сторону более сильных полей при увеличении частоты. По оси абсцисс отложено магнитное поле, нормированное на значение поля резонанса. Для удобства наблюдения по оси ординат отложена величина относительного изменения коэффициента прохождения $d_{m}$, смещенная на величину $d_{m}\left(H_{\max }\right)$, где $H_{\max }=12 \mathrm{kOe}-$ максимальная величина магнитного поля. Низкополевое крыло линии FMR значительно искажено влиянием $\mu \mathrm{GMR}$. Соотношение между полями $H_{r}$ и $H_{s}$ у сверхрешеток определяется несколькими параметрами. Поле резонанса $H_{r}$ в насыщенном состоянии зависит от намагниченности насыщения ферромагнитной компоненты $M_{s}$ и частоты микроволн $f$, а в ненасыщенном состоянии - еще от констант межслоевого обменного взаимодействия, в соответствии с формулами (2). Поле $H_{s}$ сильно зависит от толщин слоев наноструктуры и ее магнитного состояния [35]. В частности, для сверхрешеток со сплошными слоями, если толщина спейсера $(\mathrm{Cr}$ в нашем случае) соответствует параллельному упорядочению соседних ферромагнитных слоев, то насыщение достигается в полях в единицы килоэрстед, а эффект GMR мал. Это, в частности, образец 8. Если толщина спейсера соответствует антипараллельному упорядочению соседних ферромагнитных слоев, то насыщение достигается в значительно бо́льших полях, а максимальная величина эффекта GMR составляет единицы или десятки процентов. Такими являются образцы 6 и 7. Поле насыщения для сверхрешетки зависит также от числа пар слоев. Поле насыщения сверхрешеток с тонкими слоями спейсера (это образец 9) обычно больше, чем у сверхрешеток со сплошными слоями.

Приближение эффективных параметров дает возможность правильно рассчитать некоторые характеристики полевой зависимости микроволнового коэффициента прохождения через сверхрешетки. Однако это приближение не принимает во внимание спиновую поляризацию электронов, проходящих через интерфейсы сверхрешетки. Вместе с тем процессы спиновой диффузии приводят к асимметрии формы резонансной линии, как это было показано Ф. Дайсоном [22] на примере электронного спинового резонанса. В разд. 4 подробно рассмотрим асимметрию линии FMR.

\section{4. Асимметрия линии резонанса}

В работах $[23,28]$ теория была развита для случая резонанса в образце, помещенном в полый резонатор, ко- 

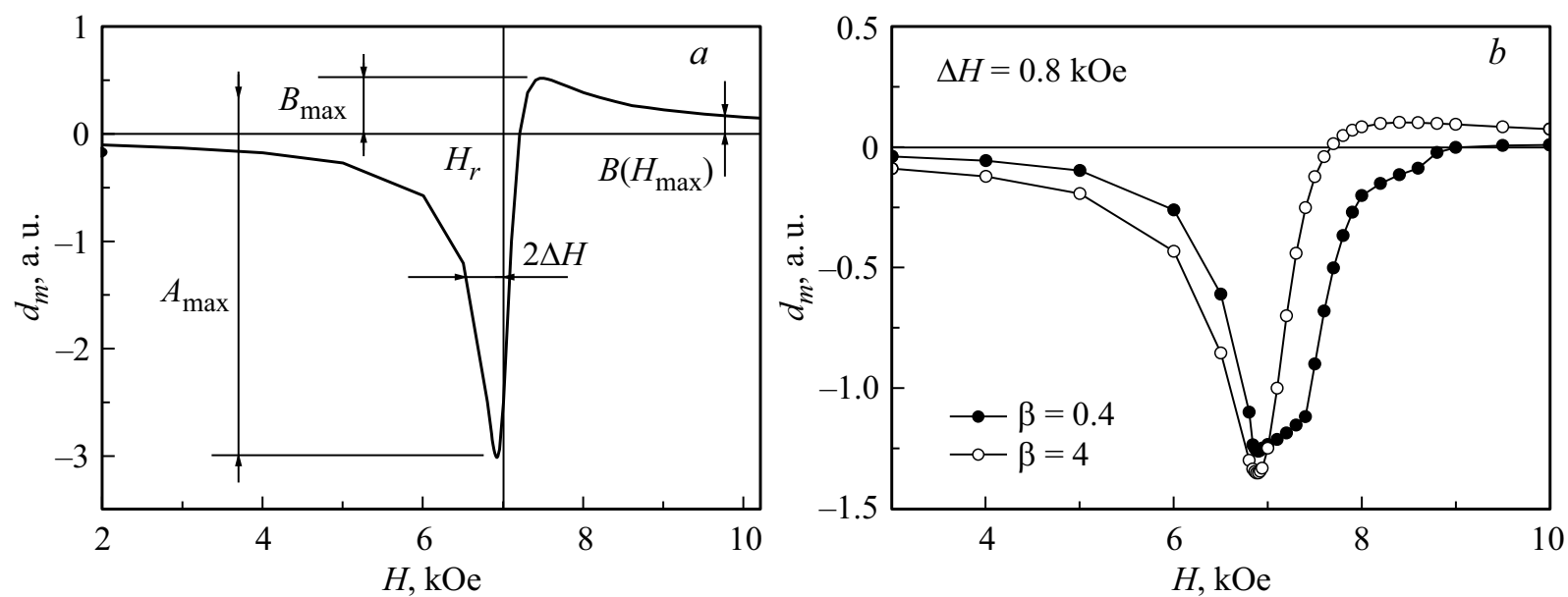

Рис. 5. Схематическое изображение формы линии ФМР в прохождении электромагнитных волн через металлическую наноструктуру (a); форма линии ФМР, рассчитанная для $H_{r}=7 \mathrm{kOe}, \Delta H=0.8 \mathrm{kOe}$, и двух значений $\beta=0.4$ и 4 (b).

гда измеряется поглощенная микроволновая мощность. В этом случае степень асимметрии линии резонанса сложным образом зависит от соотношения времени, которое требуется электрону для пересечения всего образца $T_{T}$ и времени, необходимому электрону для диффузии сквозь скин-слой $T_{D}$, а также от времени спинрешеточной релаксации [29]. Асимметрия исчезает, если $T_{T} \ll T_{D}$. Оценки показывают, что для сверхрешеток $\mathrm{Fe} / \mathrm{Cr}$ и пленок $\mathrm{Fe}$ на частотах $\sim 30-38 \mathrm{GHz}$ глубина скин-слоя $\sim 0.5-1 \mu \mathrm{m}$ превышает суммарную толщину металла наших образцов 20-80 nm. Можно было бы ожидать, что для образца № 1 с наименьшей толщиной металла $20 \mathrm{~nm}$ форма линии резонанса будет близка к симметричной лоренцевой. Однако рис. 2, $a$ показывает, что это не так. Вероятно, для правильного описания формы линии в тонких металлических объектах требуется учитывать структуру собственных волн в образце, их многократные отражения и интерференцию.

Форма линии FMR в металлических наноструктуpax асимметрична, и после минимума коэффициента прохождения, вызванного поглощением волн при FMR, осуществляется максимум. Такая структура резонансной линии позволяет представить резонансный вклад в прохождение волн в виде двух слагаемых. Первое представляет собой лоренцеву линию поглощения, а второе лоренцеву линию дисперсии. Такое представление асимметричной линии в проводящих средах использовалось, например, в работах [26,27]. Будем аппроксимировать форму линии экспериментальных резонансных линий для серии сверхрешеток и пленок по формуле

$$
\widehat{D}=-F \frac{2 \Delta H+\beta\left(H_{r}-H\right)}{4\left(H_{r}-H\right)^{2}+(2 \Delta H)^{2}} .
$$

Здесь $H$ - текущее значение магнитного поля, $H_{r}$ - поле резонанса, $2 \Delta H-$ полная ширина линии, $F>0$ - амплитудный множитель, $\widehat{D}-$ величина, пропорциональная коэффициенту прохождения. $H_{r}$ и
$2 \Delta H$ берутся из экспериментальной зависимости. При $F=2 \Delta H$ и $H=H_{r}$, т.е. точно в резонансе, получается $\widehat{D}=-F / 2 \Delta H$. Однако минимум приходится не точно на резонанс. Подгоночный параметр $\beta$ показывает долю „дисперсии“ в поглощении, т.е. регулирует степень асимметрии линии. Из экспериментальных данных получают отношение амплитуд максимума $B_{\max }$ к $A_{\max }$, т. е. $B$ max $/ A_{\max }$, а также $B\left(H_{\max }\right) / A_{\max }$, где $B\left(H_{\max }\right)-$ это амплитуда сигнала в максимальном поле (рис. $5, a)$.

На рис. 5 показаны результаты расчета, выполненного в модели, где форма линии определяется формулой (8) при $H_{r}=7 \mathrm{kOe}, \Delta H=0.8 \mathrm{kOe}$. На рис. $5, a$ схематически показана форма линии FMR в прохождении микроволн через пленку или наноструктуру. Показано положение резонанса $H_{r}$ и указаны величины минимума, т. е. максимальное отклонение $A_{\max }$ и максимума Bmax резонансной кривой. Расчет, проведенный по формуле (8), показал, что отношение $B_{\max } / A_{\max }$ зависит от $\beta$, но не зависит от $\Delta H$, что облегчает аппроксимацию экспериментальных зависимостей. На рис. $5, b$ в качестве примера показаны две зависимости формы линии, рассчитанные по формуле (8) для двух значений $\beta$. Зависимость, рассчитанная при малом $\beta=0.4$, по форме близка к лоренцевой кривой поглощения при $H<H_{r}$, но содержит максимум при $\mathrm{H}>\mathrm{Hr}$. При большом значении $\beta$ ширина резонансной линии значительно увеличивается, и искажается форма линии. Далее мы, используя формулу (8), аппроксимируем несколько типичных линий, полученных экспериментально для разных типов наноструктур.

На рис. 6, а показана экспериментально измеренная линия резонанса для пленки $\mathrm{Fe}$ (образец 1) состава $\mathrm{Cr}(3) / \mathrm{Fe}(10) / \mathrm{Cr}(7) / \mathrm{Al}_{2} \mathrm{O}_{3} \quad$ и $\quad$ еe аппроксимация по формуле (8). Видно вполне хорошее соответствие экспериментальной зависимости и аппроксимации. Единственное отличие заключается в том, что максимум коэффициента прохождения экспери- 

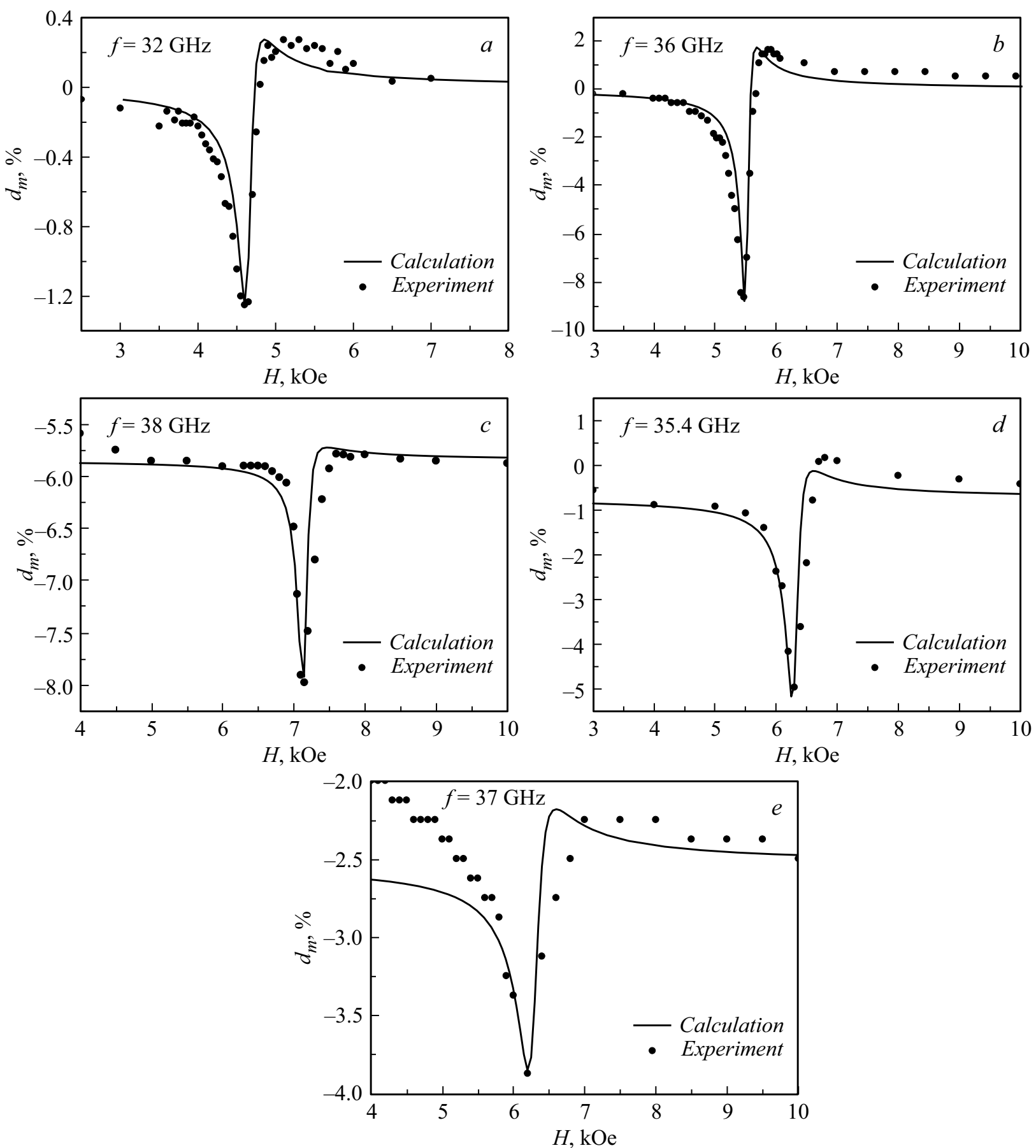

Рис. 6. Сопоставление экспериментальных и расчетных линий ФМР в прохождении волн для наноструктур разных типов: пленка $\mathrm{Fe}$, образец 1 состава $\mathrm{Cr}(3) / \mathrm{Fe}(10) / \mathrm{Cr}(7) / \mathrm{Al}_{2} \mathrm{O}_{3}$ (a); две слабо связанные пленки $\mathrm{Fe}$ образец 4 состава $[\mathrm{Cr}(10.5) / \mathrm{Fe}(14.6) / \mathrm{Cr}(4.3) / \mathrm{Fe}(14.4) / \mathrm{Cr}(9.8)] / \mathrm{Al}_{2} \mathrm{O}_{3}(b)$; сверхрешетка $\mathrm{Fe} / \mathrm{Cr}$ со сплошными слоями $\mathrm{Fe}$ и $\mathrm{Cr}$ и антипараллельным упорядочением слоев образец 5 состава $[\mathrm{Cr}(1.9) / \mathrm{Fe}(2.3)]_{12} / \mathrm{Cr}(8) / \mathrm{MgO}(c)$; сверхрешетка $\mathrm{Fe} / \mathrm{Cr}$ со сплошными слоями $\mathrm{Fe}$ и $\mathrm{Cr}$ и неколлинеарным упорядочением слоев образец 8 состава $[\mathrm{Cr}(1.8) / \mathrm{Fe}(2.8)]_{12} / \mathrm{Cr}(7.7) / \mathrm{MgO}(d)$; сверхрешетка со сплошными слоями Fе и тонкими слоями Сr образец $9[\mathrm{Cr}(0.71) / \mathrm{Fe}(2.6)]_{12} / \mathrm{Cr}(6.5) / \mathrm{Al}_{2} \mathrm{O}_{3}(e)$.

ментальной зависимости более широкий. Также хорошее соответствие наблюдается для образца состава $[\mathrm{Cr}(10.5) / \mathrm{Fe}(14.6) / \mathrm{Cr}(4.3) / \mathrm{Fe}(14.4) / \mathrm{Cr}(9.8)] / \mathrm{Al}_{2} \mathrm{O}_{3}$, состоящего из двух слабо связанных пленок $\mathrm{Fe}$ (образец 4). Эти образцы не обладают гигантским магнитосопротив- лением и в них отсутствует $\mu \mathrm{GMR}$. Данные рис. $6, c, d$ показывают сопоставление формы линии для сверхрешеток $\mathrm{Fe} / \mathrm{Cr}$, в которых есть $\mu \mathrm{GMR}$. Для сверхрешетки $[\mathrm{Cr}(1.9) / \mathrm{Fe}(2.3)]_{12} / \mathrm{Cr}(8) / \mathrm{MgO}$ со сплошными слоями $\mathrm{Fe}$ и $\mathrm{Cr}$ (образец 5) в области самого резонанса и в более 

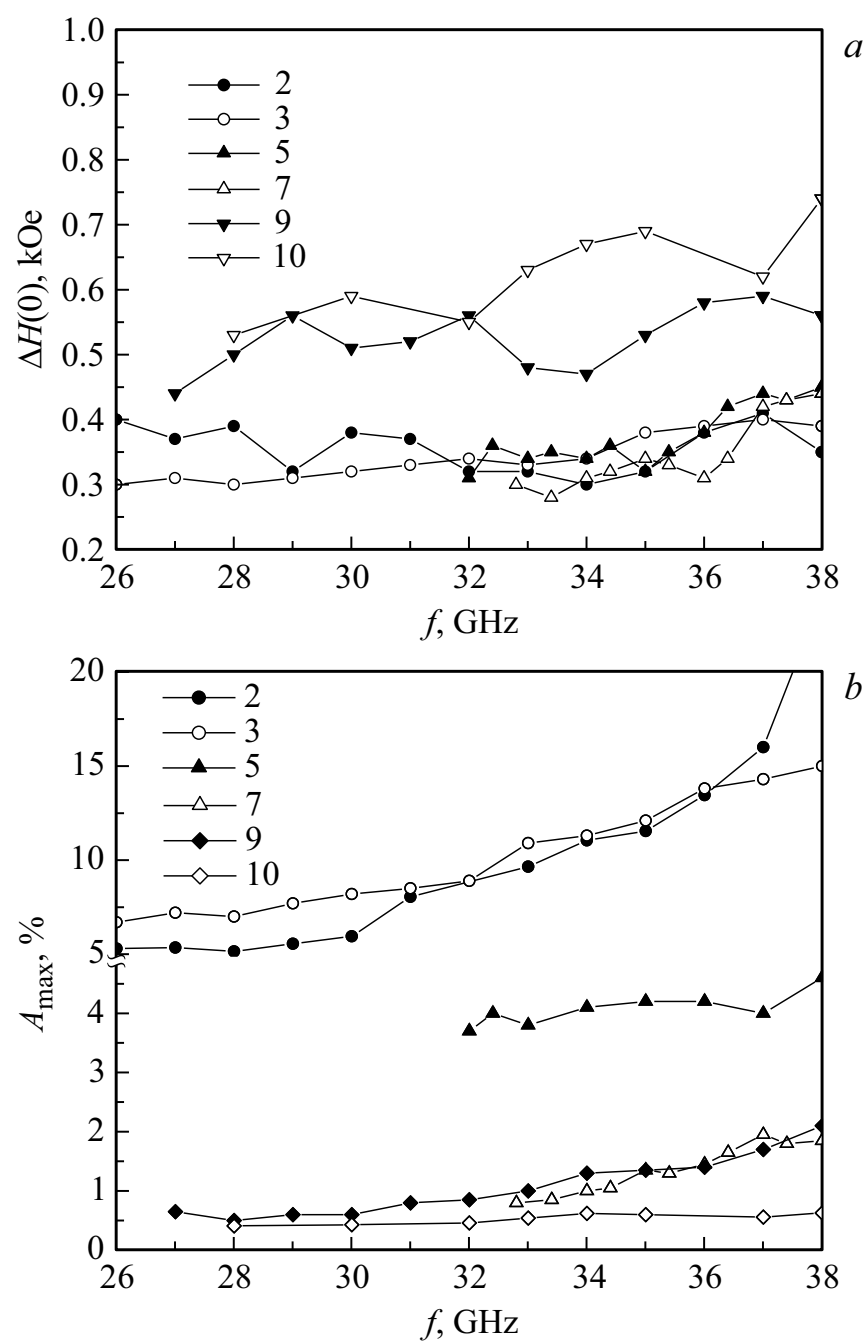

Рис. 7. Частотные зависимости ширины линии (a) и амплитуды резонанса $(b)$ для нескольких типов наноструктур.

сильных полях есть вполне хорошее соответствие эксперимента и формы линии (8), но есть расхождение слева от резонанса, в более слабых полях (рис. 6,c,d). Это расхождение вызвано изменениями коэффициента прохождения, обусловленными $\mu \mathrm{GMR}$, которые не учитываются в модели суперпозиции кривых поглощения и дисперсии (8). Для сверхрешеток со сплошными слоями $\mathrm{Fe}$ и тонкими слоями $\mathrm{Cr}[\mathrm{Cr}(0.71) / \mathrm{Fe}(2.6)]_{12} / \mathrm{Cr}(6.5) / \mathrm{Al}_{2} \mathrm{O}_{3}$ (образец 9) наблюдается худшее соответствие формы линии и аппроксимации (8) (рис. $6, e$ ). Отличие в полях, меньших $H_{r}$, связано с эффектом $\mu \mathrm{GMR}$. Отличие есть и в полях, больших $H_{r}$. Максимум при $H>H_{r}$ присутствует как на эксперименте, так и в модели (8), однако его ширина на эксперименте больше, чем на аппроксимирующей зависимости. Подобные отличия в форме линии наблюдаются у сверхрешеток с тонкими слоями железа.

На рис. 7 показаны частотные зависимости ширины линии и амплитуды резонанса для нескольких типов наноструктур $\mathrm{Fe} / \mathrm{Cr}$. C увеличением ча- стоты амплитуда резонанса в целом увеличивается. Среди всех рассмотренных образцов наименьшая ширина линии наблюдается для пленок $\mathrm{Fe}$ и сверхрешеток со сплошными слоями. Ширина линии образцов сверхрешеток с тонкими слоями $\mathrm{Cr}$ (образец 9 $\left.[\mathrm{Cr}(0.71) / \mathrm{Fe}(2.6)]_{12} / \mathrm{Cr}(6.5) / \mathrm{Al}_{2} \mathrm{O}_{3}\right)$ и тонкими слоями $\mathrm{Fe}$ (образец $\left.10 \mathrm{Cr}(0.6) /[\mathrm{Cr}(2.0) / \mathrm{Fe}(0.55)]_{30} / \mathrm{Cr}(8.0) / \mathrm{MgO}\right)$ значительно больше, вероятно, из-за значительной магнитной неоднородности. Как правило, с увеличением частоты ширина линии возрастает. Однако если на более низких частотах резонанс приходится на область полей, когда насыщение эффекта $\mu \mathrm{GMR}$ еще не наступило, a на более высоких частотах резонанс смещается в область насыщения, то частотная зависимость ширины линии становится более сложной. Это наблюдается для образцов с тонкими слоями $\mathrm{Cr}$ (образец 9) и тонкими слоями $\mathrm{Fe}$ (образец 10). Амплитуда резонансной линии наибольшая для пленок $\mathrm{Fe}$ (образцы 2 $\mathrm{Cr}(1.0) / \mathrm{Fe}(5.73) / \mathrm{Al}_{2} \mathrm{O}_{3}$ и $\left.3 \mathrm{Cr}(2.0) / \mathrm{Fe}(82) / \mathrm{Al}_{2} \mathrm{O}_{3}\right)$, она резко возрастает с ростом частоты. Наименьшая амплитуда для сверхрешеток с тонкими, возможно, не сплошными слоями либо $\mathrm{Fe}$, либо $\mathrm{Cr}$. Амплитуда резонанса для образца 10 с тонкими слоями $\mathrm{Fe}$ самая маленькая, $\sim 0.5 \%$.

На рис. 8, а показаны зависимости ширины линии $\mathrm{FMR}$ для сверхрешеток $\mathrm{Fe} / \mathrm{Cr}$ при изменении толщины слоев либо $\mathrm{Fe}$, либо $\mathrm{Cr}$. Результаты получены на частоте $f=36 \mathrm{GHz}$. При толщине $d$, превышающей $1 \mathrm{~nm}$, слои, безусловно, сплошные. При увеличении толщины как $\mathrm{Fe}$, так и $\mathrm{Cr}$ ширина линии слабо уменьшается. Подобное наблюдается и в других системах сверхрешеток, например, пермаллой-медь [36]. При $d<1 \mathrm{~nm}$ сплошность слоя сверхрешетки не гарантирована. Возникает магнитная неоднородность, и ширина линии FMR увеличивается. Для образца с $d=0$ на зависимости, полученной при изменении ширины слоев $\mathrm{Cr}$, зафиксирована малая около линии около 100 Ое. Это неудивительно, так как данный образец - пленка железа. Для образцов сверхрешеток со сплошными слоями можно по ширине линии выполнить оценку постоянной Гильберта магнитного затухания $G$ в уравнении Ландау-Лифшица по формуле

$$
\Delta H(f)=\Delta H(0)+\frac{2 \pi f}{\gamma} \frac{G}{\gamma M_{s}},
$$

где $\Delta H(f)$ - ширина линии FMR на частоте $f$, $\Delta H(0)$ - ширина линии для аппроксимации частотной зависимости ширины линии на частоте $f=0$. Зависимость постоянной Гильберта от толщины слоев хрома в сверхрешетках $\mathrm{Fe} / \mathrm{Cr}$, рассчитанная по формуле (9), показана на рис. 8, $b$. Как и следовало ожидать, наименьшее значение получается для пленки железа. Наибольшие значения $G \cong(6-7) \cdot 10^{8} \mathrm{~s}^{-1}$ реализуются для сверхрешеток с тонкими слоями хрома $d \cong(0.4-0.9) \mathrm{nm}$. При увеличении $d$ для сверхрешеток со сплошными слоями величина постоянной $G$ уменьшается до $2.8 \cdot 10^{8} \mathrm{~s}^{-1}$. Значения постоянной Гильберта для пленок и сверхрешеток со сплош- 

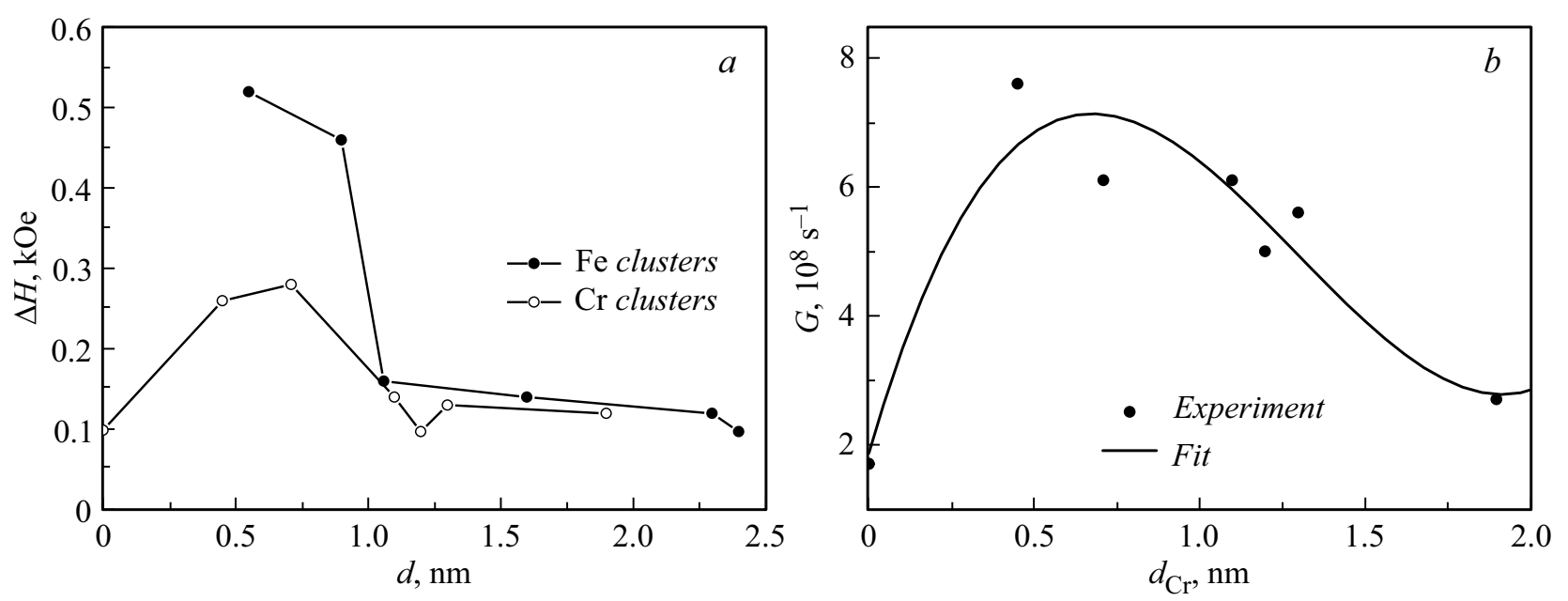

Рис. 8. Зависимость ширины линии ФМР в прохождении электромагнитных волн от номинальной толщины слоя хрома и железа $(a)$; зависимость постоянной Гильберта от толщины слоев хрома в сверхрешетках $\mathrm{Fe} / \mathrm{Cr}(b)$.

ными слоями близки к полученным в [21,37]. Погрешность определения постоянной Гильберта оценивается в $15-20 \%$.

\section{Заключение}

Исследованы изменения коэффициента прохождения микроволн через пленки и наноструктуры $\mathrm{Fe} / \mathrm{Cr}$, вызванные ферромагнитным резонансом. Амплитуда FMR наибольшая у пленок $\mathrm{Fe}$, несколько меньше у сверхрешеток с непрерывными слоями. Меньше всего амплитуда FMR у сверхрешеток с тонкими (меньше $1 \mathrm{~nm}$ ) слоями $\mathrm{Fe}$ и Cr. Ширина линии FMR наибольшая у сверхрешеток с тонкими слоями $\mathrm{Fe}$ и $\mathrm{Cr}$. На частотах микроволн $26-38 \mathrm{GHz}$ наименьшая ширина линии $\sim 0.1-0.15 \mathrm{kOe}$ у пленок и сверхрешеток со сплошными слоями. Для сверхрешеток и пленок железа рассчитана постоянная затухания Гильберта. Выполнен расчет коэффициента прохождения микроволн через наноструктуры в приближении эффективных параметров. Установлено, что гигантский магниторезистивный эффект оказывает наибольшее влияние на форму линии FMR в случае, когда поле резонанса $H_{r}$ меньше поля насыщения магниторезистивной зависимости $H_{s}, H_{r}<H_{s}$. Эффект $\mu \mathrm{GMR}$ оказывает наибольшее влияние на низкополевое крыло линии резонанса.

Проведено детальное сопоставление формы резонансной линии между экспериментальными данными и моделью, в которой асимметричная линия FMR представляется суммой двух вкладов: лоренцевой кривой поглощения и лоренцевой кривой дисперсии. Установлено, что в этой модели удовлетворительно может быть представлена форма линии пленок и сверхрешеток с непрерывными слоями. Некоторое отличие присутствует в ширине максимума, который следует после резонансного минимума. На экспериментальных зависимостях этот максимум шире, чем в модели. Для сверхрешеток с тонкими слоями $\mathrm{Fe}$ и $\mathrm{Cr}$ модель описывает экспериментальные данные только качественно. Для сверхрешеток, обладающих $\mu \mathrm{GMR}$ в полях, меньших $\mathrm{Hr}$, полевая зависимость коэффициента прохождения сильно отличается от модели, так как в ней не учтено присутствие эффекта $\mu \mathrm{GMR}$.

\section{Финансирование работы}

Работа выполнена в рамках темы „Спин“ № АAААА18-118020290104-2 и „Функция“" № АААА-A19119012990095-0. Раздел 2 выполнен при поддержке гранта РНФ № 17-12-01002.

\section{Конфликт интересов}

Авторы заявляют, что у них нет конфликта интересов.

\section{Список литературы}

[1] J.J. Krebs, P. Lubitz, A. Chaiken, G.A. Prinz. J. Appl. Phys. 69, 4795 (1991).

[2] B.K. Kuanr, A.V. Kuanr, P. Grunberg, G. Nimtz. Phys. Lett., 221A, 245 (1996)

[3] V.V. Ustinov, A.B. Rinkevich, L.N. Romashev, V.I. Minin. J. Mang. Magn. Mater., 177-181, 1205 (1998).

[4] M. Farle. Rep. Prog. Phys., 61 (7), 755 (1998).

[5] D.P. Belozorov, V.N. Derkach, S.V. Nedukh, A.G. Ravlik, S.T. Roschenko, I.G. Shipkova, S.I. Tarapov, F. Yildiz. Int. J. Infrared Milli. Waves., 22, 1669 (2001).

[6] T. Rausch, T. Szczurek, M. Schlesinger. J. Appl. Phys., 85, 314 (1999).

[7] А.Б. Грановский, А.А. Козлов, Т.В. Багмут, С.В. Недух, С.И. Тарапов. Ј.-Р. Clerc. ФТТ, 47 (4), 713 (2005).

[8] V.V. Ustinov, A.B. Rinkevich, L.N. Romashev. J. Mang. Magn. Mater., 198-199, 82 (1999).

[9] J.C. Jackuet, T. Valet. Mater. Res. Soc. Symp. Proc., 384, 477 (1995). 
[10] Z. Frait, P. Sturc, K. Tems, Y. Bruynseraede, I. Vavra. Solid State Comm., 112, 569 (1999).

[11] В.В. Устинов, А.Б. Ринкевич, Л.Н. Ромашев, Е.А. Кузнецов. Письма в ЖТФ, 33 (18), 23 (2007).

[12] D.E. Endean, J.N. Heyman, S. Maat, E. Dan Dahlberg. Phys. Rev., 84, 212405 (2011).

[13] I. Neudecker, G. Woltersdorf, B. Heinrich, T. Okuno, G. Gubbiotti, C.H. Back. J. Mang. Magn. Mater., 307, 148 (2006).

[14] M. Kostylev. Appl. Phys., 113, 053908 (2013).

[15] N.G. Bebenin. J. Mang. Magn. Mater., 161, 65 (1995).

[16] А.Б. Дровосеков, О.В. Жотикова, Н.М. Крейнес, В.Ф. Мещеряков, М.А. Миляев, Л.Н. Ромашев, В.В. Устинов, Д.И. Холин. ЖЭТФ, 116, 1817 (1999).

[17] С.О. Демокритов, А.Б. Дровосеков, Н.М. Крейнес, Х. Нембах, М. Рикар, Д.И. Холин. ЖЭТФ, 6 (12), 1233 (2002).

[18] S.O. Demokritov, A.B. Drovosekov, D.I. Kholin, N.M. Kreines, H. Nembach, M. Rickart. J. Mang. Magn. Mater., 272-276, e963 (2004).

[19] А.Б. Ринкевич, М.А. Миляев, Л.Н. Ромашев. ФММ, 120 (3), 266 (2019).

[20] A.B. Rinkevich, L.N. Romashev, V.V. Ustinov, E.A. Kuznetsov. J. Mang. Magn. Mater., 254-255, 603 (2003).

[21] В.В. Устинов, А.Б. Ринкевич, Л.Н. Ромашев, М.А. Миляев, А.М. Бурханов, Н.Н. Сидун, Е.А. Кузнецов. ФММ, 99, 486 (2005).

[22] F.J. Dyson. Phys. Rev., 15 (4), 349 (1955).

[23] G. Feher, A.F. Kip. Phys. Rev., 98 (8), 337 (1955).

[24] S.S. Kalarickal, P. Krivosik, M. Wu, C.E. Patton, M.L. Schneider, P. Kabos, T.J. Silva, J.P. Nibarger. J. Appl. Phys., 99, 093909 (2006).

[25] J.P. Joshi, R. Gupta, A.K. Sood, S.V. Bhat, A.R. Raju, C.N.R. Phys. Rev. B, 65, 024410 (2001).

[26] K.W. Joh, C.H. Lee, C.E. Lee, N.H. Hur, H.-C. Ri. J. Phys.: Condens. Matter., 15, 4161 (2003).

[27] C.T. Boone, J.M. Shaw, H.T. Nembach, T.J. Silva. J. Appl. Phys., 117, 223910 (2015).

[28] C.P. Poole, Jr. Electron Spin Resonance: a Comprehensive Treatise on Experimental Techniques (John Wiley \& Sons, NY., 1967), 780 p.

[29] H. Kodera. J. Phys. Soc. Jpn., 28 (1), 89 (1970).

[30] Н.М. Крейнес. ФНТ, 28 (8/9), 807 (2002).

[31] А.Г. Гуревич, Г.А. Мелков. Магнитные колебания и волны (Наука, М., 1994), 464 с.

[32] Н.А. Семенов. Техническая электродинамика (Связь, М., 1972), $480 \mathrm{c}$.

[33] В.В. Устинов, А.Б. Ринкевич, В.И. Гаженина, М.А. Миляев. ЖЭТФ, 158 (1), 139 (2020).

[34] A.B. Rinkevich, D.V. Perov, V.O. Vaskovsky, A.N. Gorkovenko, E.A. Kuznetsov. IEEE Trans. Nanotechnol. 16 (6), 1067 (2017).

[35] R.E. Camley, J. Barnas. Phys. Rev. Lett., 63 (6), 664 (1989).

[36] S. Mizukami, Y. Ando, T. Miyazaki. Phys. Rev. B, 66, 104413 (2002).

[37] R. Urban., G. Woltersdorf, B. Heinrich. Phys. Rev. Lett., 87 (21), 217204 (2001). 